$\$=$

\title{
Experience of a health day at the university of Namibia: A community service
}

\author{
J.M.Kloppers *, L.N. Nelumbu, T.Nauiseb, P. Angula. M.B. Tibinyane, N.G. Sumpi \\ Private Bag 13301 340MandumeNdemufaye Ave. Pionierspark. Windhoek. \\ Namibia School of Nursing and Public Health: University of Namibia \\ *Corresponding author E-mail: jkloppers@unam.na
}

\begin{abstract}
The School of Nursing and Public Health conducted an annual health day at the main campus in Windhoek. The clinic on campus was not operational, at this time. This service is much appreciated by students and staff. The Community Health Nursing lecturers and second year diploma students participated in the Health day. The services that were rendered included blood pressure; weight and height and body mass index; blood-glucose test; eye test; neck massage. Health education on HIV/AIDS and cancer prevention was given to those who took part. The health day targeted non-communicable diseases (NCD) in order to promote prevention strategies. NCD is a medical condition or disease that can be defined as non-infectious and non-transmissible among people. It is further described as chronic diseases which last for long periods of time and progress slowly. Sometimes, NCDs result in rapid deaths as seen in certain types of diseases such as autoimmune diseases, heart diseases, stroke, most cancers, asthma, diabetes, chronic kidney disease, osteoporosis, Alzheimer's disease, cataracts, and many more (World Health Organization (WHO).

Aim: The health day was done to promote and to provide necessary information and to raise awareness to students and staff on their health and on how to prevent non-communicable diseases.

Method: No actual research was done.

Results: Data analysis was done based on the findings from the users of the service. The total number of the people who used the blood pressure service were 161. Of which 38 were found to have high blood pressure while 10 were found with low blood pressure and were advised to visit the hospital or clinic and 113 had normal blood pressure. Many people, who were detected with high blood pressure, or hypertension, had no idea of having it. The people who came for weight were 130 out of which 63 had normal weight, 32 were overweight, 16 were obese, and 15 were underweight. Health education was given on nutrition, specifically on balance diet. 20 people were found with high blood-glucose level ranging between 7-21.8 mml. Total number of people who attend eye test were 63 of which 4 had poor vision and were referred to eye clinic. Neck massage attracted many people, and they enjoyed it.

Conclusion: The results of health day indicated the need of such services in order to detect abnormalities and to improve the knowledge and understanding of the community members on non-communicable diseases and how to prevent them.
\end{abstract}

Keywords: Health Day; Non-Communicable Diseases.

\section{Introduction}

One of the core functions of the University of Namibia for lectures is to do community service. The community lecturers conducted a Health day at Windhoek campus. The Health day was conducted to raise awareness among learners and staff to care for their health and to prevent NCD. Non- communicable diseases are also known as chronic diseases. They are passed on from person to person and are long in duration. They are generally slow in progression. The 4 main types of non-communicable diseases are cardiovascular diseases (like heart attacks and stroke), cancers, chronic respiratory diseases (such as chronic obstructed pulmonary disease and asthma) and diabetes (Lim, Vos, Flaxman, Danaei, Shibuya, AdairRohani et al). According to the Cancer Association, (2009), it was indicated that in April 2009 to March 2010, 275 cases of breast cancer were recorded. Globocan, (2008) stated that nearly 1.4 million cases of breast cancer were diagnosed across the world in 2008.
Under the leadership of the World Health Organization (WHO) more than 190 countries agreed in 2011 on global mechanisms to reduce the avoidable NCD burden, including a Global action plan for the prevention and control of NCDs 2013-2020. In 2015, countries will begin to set national targets and measure progress on the 2010 baselines reported in the Global status report on non- communicable diseases 2014.

The key points of non-communicable diseases are as follows:

- Non- communicable diseases (NCDs) kill 38 million people each year. (Preventing Chronic Diseases a Vital Investment" World Health Organization, 2005).

- Almost three quarters of NCD deaths - 28 million - occur in low- and middle-income countries.

- Sixteen million NCD deaths occur before the age of 70; $82 \%$ of these "premature" deaths occurred in low- and middleincome countries.

- Cardiovascular diseases account for most NCD deaths, or 17.5 million people annually, followed by cancers ( 8.2 million), respiratory diseases (4 million), and diabetes ( 1.5 million). 
- These 4 groups of diseases account for $82 \%$ of all NCD death (Mozaffarian D, Fahimi S, Singh GM, Micha R, Khatibzadeh S, Engell RE, Lim, 2014).

Tobacco use, physical inactivity, the harmful use of alcohol and unhealthy diets all increase the risk of dying from an NCD. Tobacco accounts for around 6 million deaths every year (including from the effects of exposure to second-hand smoke), and is projected to increase to 8 million by 2030 .

These behaviors lead to four keys metabolic/physiological changes that increase the risk of NCDs: raised blood pressure, overweight/obesity, hyperglycemia (high blood-glucose levels) and hyperlipidemia (high levels of fat in the blood). The body naturally tightly regulates blood-glucose levels as a part of metabolic homeostasis. The normal blood-glucose level (tested while fasting) for non-diabetics, should be between 3.9 and $5.5 \mathrm{mmol} / \mathrm{L}$ (70 to $100 \mathrm{mg} / \mathrm{dL}$ )(Tunstall- Pedoe, 2005).

\section{Method}

No research was done. The activities were performed in the library foyer. All students and staff entering the library were the target population.

\subsection{Ethical issues}

Students and staff were informed by email and posters about the date and time and venue of the health day. The principles of anonymity, autonomy and confidentiality were adhered to.

\section{Discussion}

\subsection{Results}

Table 1: Blood Pressure Monitoring

\begin{tabular}{ll}
\hline Male & Fe-male \\
\hline 45 & 116 \\
\hline
\end{tabular}

These numbers are student and staff whose blood pressure were monitored. The University have more female than male students.

Table: 2 Measuring of Blood Pressure

\begin{tabular}{lll}
\hline Blood Pressure Levels & Total & Reading \\
\hline High Blood Pressure & 1 & $170 / 104$ \\
& 6 & $150 / 89-151 / 97$ \\
& 5 & $140 / 90-149 / 108$ \\
Low Blood Pressure & 26 & $130 / 80-139 / 82$ \\
Normal Blood Pressure & 10 & $89 / 50-97 / 61$ \\
\hline
\end{tabular}

Table 3: Body Mass Index

\begin{tabular}{ll} 
& Table 3: Body Mass Index \\
\hline Male & Female \\
\hline 34 & 96 \\
\hline
\end{tabular}

\begin{tabular}{ll}
\multicolumn{2}{c}{ Table 4: Body Mass Index } \\
\hline Normal weight & 63 \\
\hline Over weight & 32 \\
Obese & 16 \\
Under weight & 15 \\
No length taken & 96 \\
\hline
\end{tabular}

Table 5: Blood Glucose Level

\begin{tabular}{ll}
\hline Male & Female \\
\hline 39 & 102 \\
\hline Age range from 18yrs -56yrs &
\end{tabular}

Age range from $18 \mathrm{yrs}-56 \mathrm{yrs}$
Table 6: Blood Glucose Level

\begin{tabular}{lll}
\hline \multicolumn{2}{c}{ Table 6: Blood Glucose Level } & Total \\
\hline Very High (on Treatment) & Reading & 1 \\
High & $21.8 \mathrm{mmol}$ & 14 \\
& $6.0-6.12 \mathrm{mmol}$ & 4 \\
& $7 \mathrm{mmol}$ & 1 \\
& $9 \mathrm{mmol}$ & 1 \\
Normal & $11 \mathrm{mmol}$ & 120 \\
\hline
\end{tabular}

Table 7: Eye Testing

\begin{tabular}{ll}
\hline Male & Female \\
\hline 15 & 48 \\
\hline
\end{tabular}

Table 8: Testing of Eye Vision

\begin{tabular}{|c|c|}
\hline \multicolumn{2}{|c|}{ Normal vision: 59} \\
\hline Weak vision: 2 & $20 / 30$ which is 9.4 metre \\
\hline 1 & $20 / 25$ which is 7.62 metres \\
\hline 1 & $20 / 50$ which is 15.2 metres \\
\hline
\end{tabular}

Table 9: Neck Massage

\begin{tabular}{ll}
\multicolumn{2}{c}{ Table 9: } \\
\hline Male & Female \\
\hline 26 & 62 \\
\hline
\end{tabular}

Table 10: Age Group for Neck Massage

\begin{tabular}{lll} 
& Table 10: & Age Group for Neck Massage \\
\hline YEARS & TOTAL & Percentages \\
\hline $18-22$ years & 24 & $30 \%$ \\
23-29 years & 16 & $20 \%$ \\
30-34 years & 14 & $17 \%$ \\
36-42years & 13 & $16 \%$ \\
43-56 years & 14 & $17 \%$ \\
& 81 &
\end{tabular}

The age range was from 18 years up to 56.

\subsection{Health education}

\subsubsection{Students and staff experience and knowledge on HIV/AIDS}

Students and staff knowledge were tested with a questionnaire. Students show a very good understanding on HIV and other sexually transmitted infections. Students were confident in answering and asking questions. However, students required more explanation or clarity on the importance of PMTC programmes, such as how can these programmes could prevent HIV transmission from mother to child if breast milk is also a bodily fluid. The following questions were also raised by students:

- Can we trust our HIV testing kits?

- How many types of HIV tests do we conduct in Namibia

- Is it possible that one will get infected with HIV if one sleeps once with someone that is infected?

The interviews went well and students requested for more such events and also to be tested for HIV.

\subsubsection{Knowledge on cancer}

Students and staff were made aware of the early signs of cancer. The dangers of smoking were emphasized and models depicting normal, cancerous and emphysemic lungs were available for viewing. Female students were shown how to examine their breasts. Male student were educated on prostate cancer.

\subsection{Blood pressure monitoring}

The total number of the people who used the blood pressure service were 161 . Of which 38 were found to have high blood pressure while 10 were found with low blood pressure and were advised to visit the hospital or clinic and 113 had normal blood pressure. Many people who was detected with high blood pressure, or hypertension, had no idea of having it. Most of the time, there are no symptoms, but when high blood pressure goes untreated, it damages arteries and vital organs throughout the body. That's why high blood pressure is often called the "silent killer. The American Heart Association recommends that blood pressure screening need 
to start at the age of 20 years once every second year. At your regular healthcare visit or once every 2 years.

Blood pressure should be less than 120/80 mm $\mathrm{Hg}$ (less than 120systolic and less than 80 diastolic) for an adult age 20 or over. When blood pressure reading is higher than normal. Your health provider will measure your blood pressure several times before diagnosing you with high blood pressure American Heart Association (2015).

\subsubsection{Body mass index}

The people who came for weight were 130 out of which 63 had normal weight, 32 were overweight, 16 were obese, and 15 were underweight. Health education was given on nutrition specifically on balance diet. Body Mass Index (BMI) is a number calculated from a person's weight and height. BMI provides a reliable indicator of body fatness for most people and is used to screen for weight categories that may lead to health problems (Kedrick, 2015). According to Ministry of Health and social services MoHSS, (2013) overweight can be measured by relating the weight to height from which the BMIis calculated. BMI=weight in Kilogram over height in $\mathrm{m} 2$ e.g. $\mathrm{BMI}=66 \mathrm{~kg}$ over $1.68 \mathrm{X} 1.68$ Obesity is a condition that develops due to prolonged imbalance between energy intake and energy expenditure. A person is obese when BMI is greater than $>-30$. There are number of factors that contribute to the risk of overweight or obesity like: Genetic makeup; food choices; cooking methods using a lot of fat or oil; lack of physical activities and malnutrition in early stage of life. It is recommended for people to eat a variety of vegetables and fruit reduce fatty food, drink alcohol in moderation and to avoid missing breakfast.

\subsubsection{Blood glucose level}

Twenty (20) people were found with high blood glucose level ranging between 7-21.8 $\mathrm{mml}$ out of 141 blood gluco test that was done.

The blood sugar concentration or blood glucose level is the amount of glucose (sugar) present in the blood of a human or animal. The mean normal blood glucose level in humans is about $5.5 \mathrm{mmol} / \mathrm{L}(100 \mathrm{mg} / \mathrm{dL})$. Vital Investment Glucose is transported from the intestines or liver to body cells via the bloodstream, and is made available for cell absorption via the hormone insulin, produced by the body primarily in the pancreas. A body's homeostatic mechanism, when operating normally, restores the blood sugar level to a narrow range of about 4.4 to $6.1 \mathrm{mmol} / \mathrm{L}$ ( 79.2 to $110 \mathrm{mg} / \mathrm{dL}$ ) (as measured by a fasting blood glucose test) done in the laboratory(Tunstall- Pedoe, 2005).

However, this level fluctuates throughout the day. A condition where the blood sugar level drop to low is called hypo-glycaemia which is a potentially serious condition (Tunstall- Pedoe, 2005).

The symptoms may include lethargy, impaired mental functioning; irritability; shaking, twitching, weakness in arm and leg muscles; pale complexion; sweating; paranoid or aggressive mentality and loss of consciousness. If the blood sugar levels remain too high the body suppresses appetite over the short term. Long-term hyperglycemia. The most common cause of hyperglycemia is diabetes. Physicians typically recommend an anti-diabetic medication as treatment. From the perspective the majority of patients, treatment with an old, well-understood diabetes drug such as metformin will be the safest .Consumer reports health best buy drugs (2012).

\subsubsection{Eye testing}

Total number of people who attended eye test were 63 of which 4 had poor vision and were referred to eye clinic.

Vision is closely linked to the learning process. Students as well as children with undetected vision problems often will have trouble with their schoolwork. Most of times, children will not complain of vision problems simply because they don't know what "normal" vision looks like.
According to Heitung and Palombi (2000), person need to make sure that during a comprehensive eye exam, your physician must also check the eyes for common diseases and not only prescription for eyeglasses or contact lenses. Your eye care professional can tell if you have macular edema or any stage of diabetic retinopathy. Whether or not you have symptoms, early detection and timely treatment can prevent vision loss (National Eye Institute, (2012).

The National Eye Institute, (2012) declare that some diseases for diabetes is as follows: Diabetic retinopathy damage to the blood vessels in the retina and it can lead to blindness. Cataract is clouding of the eye's lens. The practitioners often are the first health care professionals to detect chronic systemic diseases such as high blood pressure and diabetes. Cataracts develop at an earlier age in people with diabetes. Glaucoma increase in fluid pressure inside the eye that leads to optic nerve damage and loss of vision. A person with diabetes is nearly twice as likely to get glaucoma as other adults.

\section{3.5. Neck massage}

Neck massage attracted many people and they enjoyed it. Students and staff who attended were eighty eight (88) in total.

Students become very stressful due to all the pressure of their studies, assignments and social problems. According to Massage Management for Stress Relief (2005-2015) neck massage is apply to ease headache and stress. Technic is as follows by placing your thumbs on your cheekbones close to your ears, and use your fingertips to gently apply pressure and rub the temples (the soft spot between the corner of your eye and your ear). By using very firm pressure and a tiny circular motion, gradually move your fingers up along your hairline until they meet in the middle of your forehead, massaging your entire forehead and scalp as you inch along.

\subsubsection{Health education}

Health education is any combination of learning experiences designed to help individuals and communities improve their health, by increasing their knowledge or influencing their attitudes. World Health Organization WHO (2015) describes health education as a profession of educating people about health. Areas within this profession encompass environmental health, physical health, social health, emotional health, intellectual health, and spiritual health. McKenzie, Neiger, Thackeray, (2009). Health education was done on prevention of cancer, smoking, balance diet and exercise.

\subsubsection{Knowledge on HIV/AIDS}

HIV is a well-known topic. The University of Namibia has a subject contemporary issues that is compulsory for all students in their first year to learn more on HIV/AIDS. Quiz was used with 14 questions to test student's knowledge. Students enjoyed to be asked questions on HIV/AIDS Participants also reveal personal problems that they experienced.

\subsubsection{Knowledge on cancer}

Awareness was raised for students to know the seven danger signs of cancer and also know how to examine the breast (Cancer Association of Namibia, 2009).Pamphlets were distributed among students about skin cancer, prostate, breast and lung cancer. A model which came from Cancer Association indicates three types e.g. Normal Lungs; Emphysema and Cancer was used to demonstrate how the normal and sick lungs functioning. Some students that were smoking said they will quit smoking immediately after seeing these affected lungs. 


\section{3. 9. Challenges}

The period spent in the field is short. Shortage of strips for glucose test and cholesterol. Students request that the health day is a good thing seeing that the clinic is closed at the University.

\section{Conclusion and recommendations}

Health days are very important for students at the university level Many students and staff don't make time to go for their yearly checkup. The recommendation of the students were to have more health days. Students and Staff suggested that the Health days must be done regularly.

\section{Acknowledgement}

Our sincere gratitude to the following people:

Lectures and $2^{\text {nd }}$ year Diploma students for their participation in the health day.

To our senior administrative officer for arranging for the posters and food.

The library so that the team can use their facilities.

The cancer association for providing the model of the lung with different diseases and pamphlets.

The transport service for bringing students to the venue and back to nurses' homes.

\section{References}

[1] American Heart Association (2015) Understanding Blood pressure Reading heart.org/heartorg/conditions/ HighBloodpressure Greenville 7272 Dallas TX $75231 \mathrm{hh}$.

[2] American Heart Assosoiation (2015) Symptoms Diagnosis \& Monitoring of High "Chronic diseases" World Health Organization Reports health.

[3] Cancer Association of Namibia (2009) Beat Breast Cancer. Keep in touch. Available at: http://can.org.na/wpcontent/uploads/breastcancer\%pdf.

[4] Coalition of National Health Education Organizations. Introduction. Health Education Code of Ethics. November 8, 1999, Chicago, IL. Retrieved May 1, 2009, from http://www.cnheo.org/code3.pdfrminology". American Journal of Health Education32 (2): 89-103.

[5] Consumer Reports Health Best Buy Drugs The Oral Diabetic Drugs: Treating Type 2.

[6] GLOBOCAN, (2008) Cancer Statistics Breast Cancer Worldwide.WCRF International Second Floor 22 Bedford Square,London.http://globocan.iarc.fr351-9.

[7] Heitung, G. and Palombi, J. (2000).Why Eye Exams Important.http://www.allaboutvision.com/eye-exam/importa. Accessed $(06 / 05 / 2015$

[8] Jump up ^"Screening for Type 2 Diabetes". Clinical Diabetes 18 (2). $2000 . \quad \mathrm{http}: / /$ journal.diabetes.org/clinical diabetes/v18n22000/pg69.htn.

[9] Lim SS, Vos T, Flaxman AD, Danaei G, Shibuya K, Adair-Rohani H et al. (1990-2010) A comparative risk assessment of burden of disease and injury attributable to 67 risk factors and risk factor clusters in 21 regions,: a systematic analysis for the Global Burden of Disease Study 2010. Lancet, 2012; 380(9859):2224-2260 http://dx.doi.org/10.1016/S0140-6736(12)61766-8.

[10]Malcolm Kendrick (April 12, 2015) "Why being 'overweight' mean you live longer: The way scientists twist the facts". http://www.independent.co.uk. 10158229, html. Retrieved 12 April 2015.

[11]Massage Management for Stress Relief (2005-2015) Web MD health services http://wwwwebmebmd.com/balance/stress-management.

[12]McKenzie, J., Neiger, B., Thackeray, R. (2009) Health education can also be seen as preventivemedicine(marcus 2012). Health Education and Health Promotion. Planning, Implementing, \& Evaluating Health Promotion Programs. (pp. 3-4). 5th edition. San Francisco, CA: Pearson Education, Inc.

[13]Mozaffarian D, Fahimi S, Singh GM, Micha R, Khatibzadeh S, Engel RE, Lim S et al.; Global Burden of Diseases Nutrition and Chronic Diseases Expert Group. Global sodiumconsumption and death from cardiovascular causes. N Engl J Med. 2014; 371 (7):624-34 http://dx.doi.org/10.1056/NEJMoa1304127.

[14]Ministry of Health and Social Services (2013) Nutrition Guidelines for Prevention and Management of Non-Communicable Diseases, Windhoek. Namibia.

[15] National Eye Institute (NEI) (June 2012) Research today.... Vision tomorrow. Department of Health and Human Science https://www.nei nih.gov/health/diabetic/retinopati.

[16]TunstalPedoe, H. (2006)Preventing Chronic Diseases a Vital Investment". Cataloguing-in-Publication Data (World Health Organisation) International Journal ofEpidemiology.

[17]Health Organization). $2005 \wedge$ Jump up to: ${ }^{a b}$ what are $\mathrm{mg} / \mathrm{dl}$ and $\mathrm{mmol} / \mathrm{l}$ ? How to convert? Glucose? Cholesterol? Advameg, Inc.

[18]Physical Status: The use and Interpretation of Anthropometry (pdf) PDF). WHO Technical Report Series (Geneva, Switzerland: World Health Organization) 854: 9. 1995.

[19]World Health Organization WHO (2015) Health Education. 